\title{
Situation Analysis and Countermeasures during the Promotion of International Trade Cooperation in Cultural Industry
}

\author{
Juanli Lan ${ }^{1, a,{ }^{*}, \text { Hongzhen Lei }}{ }^{2, b}$,Zhiyu Tian ${ }^{3, c}$ and Wangyue Zhang ${ }^{4, d}$ \\ 1,2,3 International Business School, Shaanxi Normal University,Xi'an,710119,China \\ ${ }^{4}$ Qin Nong Bank,Chan Ba Branch \\ a lanjuanlimutou@163.com, b leihongzhen@21cn.com, c514166887@qq.com \\ dzhangwangyue885353@163.com *Corresponding author
}

Keywords: cultural products; international outsourcing; foreign trade; One Belt One Road

Abstract. With the further development of cultural products in foreign trade, China's cultural products are bound to face competition in the international market. The cooperation of cultural products in international trade, which make cultural products has become one of the new form and important way to participate in the international competition gradually, and also has important strategic significance especially on the development of culture industry, cooperation of international trade, construction in One Belt One Road, improvement of China's indigenous innovation ability and so on. In view of the mistakes and problems which China have met at present, presented that we should work together from three aspects of environment, talents and risk for the international trade cooperation, in order to provide several Suggestions for promoting the development of internationalization in China's cultural enterprises to click into plexpert .

\section{Introduction}

After the Kung Fu Panda, Mulan and so on large-scale cultural products successfully entered the international market, more and more cultural products began to realize by the development and promotion of international enterprises' cooperation, international outsourcing is gradually becoming one of the important forms of cultural enterprises international trade cooperation, such film and television entertainment industry as the representative of International Culture industry trade also subsequently rise.Through international outsourcing, transnational corporations in developed countries can strengthen its core capabilities, improve operational efficiency, and reduce operating costs and share operating risks. Through international outsourcing, developing countries can give full paly to the comparative advantage, promote the improvement of labor productivity and the level of industrial technology upgrading, so as to promote industrial upgrading ${ }^{[1]}$. China as one of the biggest developing countries, because it has a large population base, rich cultural implication, cultural industries skilled production level etc. gradually get more attention of these cultural products international trade cooperation and developed rapidly.

\section{The Strategic Significance of International Trade Cooperation in Culture Industry}

\subsection{The necessary way for the development of culture industry}

Under the background of the rapid development in intra-product specialization, international industrial transfer modes are gradually evolving from vertical FDI oriented to international outsourcing oriented, the reason why international culture industry trade chooses outsourcing to outsource is the obvious advantages of outsourcing, such as improving operation efficiency, reducing operating costs and sharing operational risks, mainly includes the production of culture industry related products, software, technology research and information technology services etc. And it is divided into two types: foreign outsourcing and undertake outsourcing.

Through culture products international outsourcing can vigorously develop culture industry, on the one hand, China can use its comparative advantage as Contracting Party, actively undertake culture products outsourcing project and extend China undertake outsourcing of content, makes 
China contracting content not just limited labor intensive products, also can gradually develop technology intensive products; on the other hand, in the culture products international outsourcing cooperation, outsourcing out weak part of the technology in our cultural products production, for the completed outsourcing production of cultural products study efforts and learn advanced technologies of developed countries, and constantly raise the level of China's cultural products manufacturing technology.

\subsection{The practical demand of international trade cooperation}

Though outsourcing strategy enterprises can reduce costs and improve efficiency, and based on the full development of their core competence integration and utilization of external best professional resources, if this mode of operation has broken through national boundaries it called offshore outsourcing. Calculation of current outsourcing based on export or import trade statistics data, from the perspective of undertaking adopt the export data, that is, to undertake foreign contracts; on the contrary, calculation from the perspective of outsourcing to consider, should use imported data ${ }^{[2]}$, so the international outsourcing of cultural products is a new form of international trade.

Studies have shown that outsourcing has the biggest impact on capital intensive products, followed by labour-intensive, resource-intensive impact was minimal, acceptable in the outsourcing of China, capital intensive products significantly more labour-intensive products, and most of the production of labour-intensive products in the world has shifted to developing countries $^{[3]}$.International outsourcing of culture products belongs to offshore outsourcing, and also develops based on comparative advantage and scale economy, whether it is the culture products outsourcing or the China's undertaking foreign outsourcing projects of cultural products, it will have a certain impact on exports structures, China wants to change the outsourcing situation at present, that is mainly rely on labor intensive comparative advantage can play our own cultural advantages and technical expertise and attract more developed countries and some developing countries to cooperate in the cultural products outsourcing, prompt China's export commodity structure change, provide new power sources to promote the international development of China's culture enterprises and achieve the cooperation of international cultural products trade .

\subsection{Play our own comparative advantage, service the new ideas of “One Belt and One Road" construction}

"One Belt and One Road" is a community of interests, which is rely on the existing bilateral multilateral mechanism between China and the countries concerned, using existing, proven platform for regional cooperation, initiative to develop economic cooperation with countries along the partnership, together to build political mutual trust, economic integration and cultural inclusion, as shown in Figure 1, Silk Road including the overland Silk Road and Maritime Silk Road, is a country with a long history and profound cultural connotation of the concept of space and cultural concepts.. The Silk Road culture which is under the pattern of "One Belt and One Road" is common cultural memory and cultural symbol of countries and regions along the line, it is also a combination of deep blend of different countries' cultures along the line ${ }^{[4]}$.

It is due to most of the countries along "the Belt and Road" has a long history of culture, cultural products can become a new opportunity for outsourcing cooperation, therefore our country should be committed to the expansion of outsourcing content, not only limited to the legal, transportation, catering and other traditional service outsourcing, and should pay more attention to develop international outsourcing of cultural products, let cultural products manufacturing and IT service, training and public relations together into outsourcing new growth areas, encouraging and supporting our country with countries along "The Belt and Road" mutual cooperation to implement cultural product outsourcing and outsourcing is essentially an external transfer of "input link activities", rather than "output activities" as a whole ${ }^{[5]}$,China should play its comparative advantage, undertake the transnational cultural products outsourcing projects initiatively, or find compare expertise areas of countries along the route to take part in foreign outsourcing, absorb the beneficial ingredients of excellent foreign culture, this does not affect the Chinese creation, but it is to realize the communications and mutual learning between different civilizations with concrete actions, to 
create a new platform for culture industry, serve "The Belt and Road" cultural construction, to ultimately achieve the prosperity and development of our culture in the world.

\subsection{The important driving force to improve local technological innovation}

Outsourcing can not only effectively help enterprises to reduce costs, improve efficiency, but also can be in the full development of their core competence based, integrated use of external most outstanding specialized resources and enhance its ability to respond rapidly to the environment, form effective enterprise strategy. Zhang Qiu ju etc. (2008) through empirical analysis obtained that there is a long-term stable relationship between international outsourcing and technology progress, in the long run, technological progress is the reason for the promotion of international outsourcing. In the short term, international outsourcing is the reason for the promotion of technological progress $^{[6]}$. There also have studies shown that scientific research personnel accounting for in the industry positive correlation with outsourcing, outsourcing leads to the development of human resources allocation to the direction of the local technology innovation, this point in the cultural product outsourcing has been verified, because the development of the culture industry depends on the progress of scientific research. On the one hand, whether it is cultural products to undertake projects of foreign outsourcing or outsourcing, are able to change the structure of the domestic market, reducing the strength of domestic R\&D market, forcing the domestic R\&D department to face the crisis that has been replaced by foreign competitors, it is necessary to speed up R\&D speed, thus promoting domestic technological innovation; at the same time, domestic producers can learn more and better cultural products manufacturing technology, and further stimulate the progress of culture industry technology. as well as an important driving force for local technological innovation $^{[7]}$.

\section{Main misunderstandings and problems}

The Fifth Plenum of the 17th Central Committee of the Communist Party of China proposed during "12th Five-Year Program for China's Economic and Social Development (2011-2015)/12th Five-Year Plan" period to " promote cultural industries become the pillar industries for the national economy" this strategic goal, which makes the realization of international enterprise cultural products outsourcing cooperation particularly important in the process of forming an effective competition in the international culture industry outsourcing market.

\subsection{Some countries along "The Belt and Road" highlighted international trade issues}

Countries alone "The Belt and Road" not only developed countries like the US, Europe, Japan, Hong Kong, it also includes the countries along " Silk Road Economic Belt ", China and some of the most important trade partners, including the "Russia, Kazakhstan, Uzbekistan, Kyrgyzstan, Tajikistan, Turkey" trade cooperation is still in its infancy, there are many problems, at present, the main problems as follows.

First, although China and the countries along the route initially established "four in one" comprehensive transportation network, but cross-border transport coordination mechanism is not perfect, there are many obstacles to major transport trunk, multilateral transport failed to achieve the desired state, involving many countries and countries in traffic transportation technology standards are not uniform resulting in greatly increased transport costs; secondly, Russia and the countries along the route have established a variety of economic union, especially Russia, the white, Kazakhstan customs union, restrict the penetration of foreign economic forces through strict trade barriers and other means, The three countries unified trade policy, form inherent pattern of interests between the allies, unified import tariffs for countries outside the alliance, increasing the difficulty of competing in other countries; finally, some countries along the "Silk Road Economic Belt" set technical barriers to trade for awareness of the Chinese enterprises and products , in the actual trade, there are frequent changes in the policy by the other, different caliber of law enforcement and other outstanding problems. These problems is not only to achieve "The Belt and Road" strategic decision must be faced, it will also become a major challenge constraining China and countries along the 
"Silk Road Economic Belt" in all trade cooperation, including cultural industries ${ }^{[8]}$.

\subsection{Slow development of cultural enterprises}

With the rapid growth of the domestic economy and the continuous expansion of the import and export trade, China has gradually become one of the most important economic bodies leading the development of Global trade. As shown in Figure 2, China's international trade development is in rapid growth momentum, the foreign economic cooperation for import and export volume ratio are also in a rising trend, the scale of trade is also growing.

However, it is undeniable that the internationalization of China's cultural enterprises (cultural enterprises that enterprises engaged related to the content of the culture industry) is still slow development, the specific performance of: first, the international development of cultural enterprises form and content is relatively simple, narrow cultural products export market, in the conventional cultural products in international trade, exports of cultural goods are mainly concentrated in the traditional culture of processing and manufacturing, especially for the development of special cultural resources and the level of management planning, cultural integration and creative ability have to be improved. Secondly, the industrial structure is mainly concentrated in the low level of processing trade and service outsourcing, cultural products lack of internal innovation ability and international competitiveness of core technology; finally, international trade of China's culture industry too much emphasis on "going out" and the lack of "Introduction to" courage, the introduction of international capital, technology, management and other elements are not enough, not well play our comparative advantage to attract foreign cultural products technology outsourcing project, the lack of transform the comparative advantages into competitive advantage, continuously for a long time, the culture industry of our country is difficult to occupy a seat in the pattern of international culture industry competition ${ }^{[9]}$.

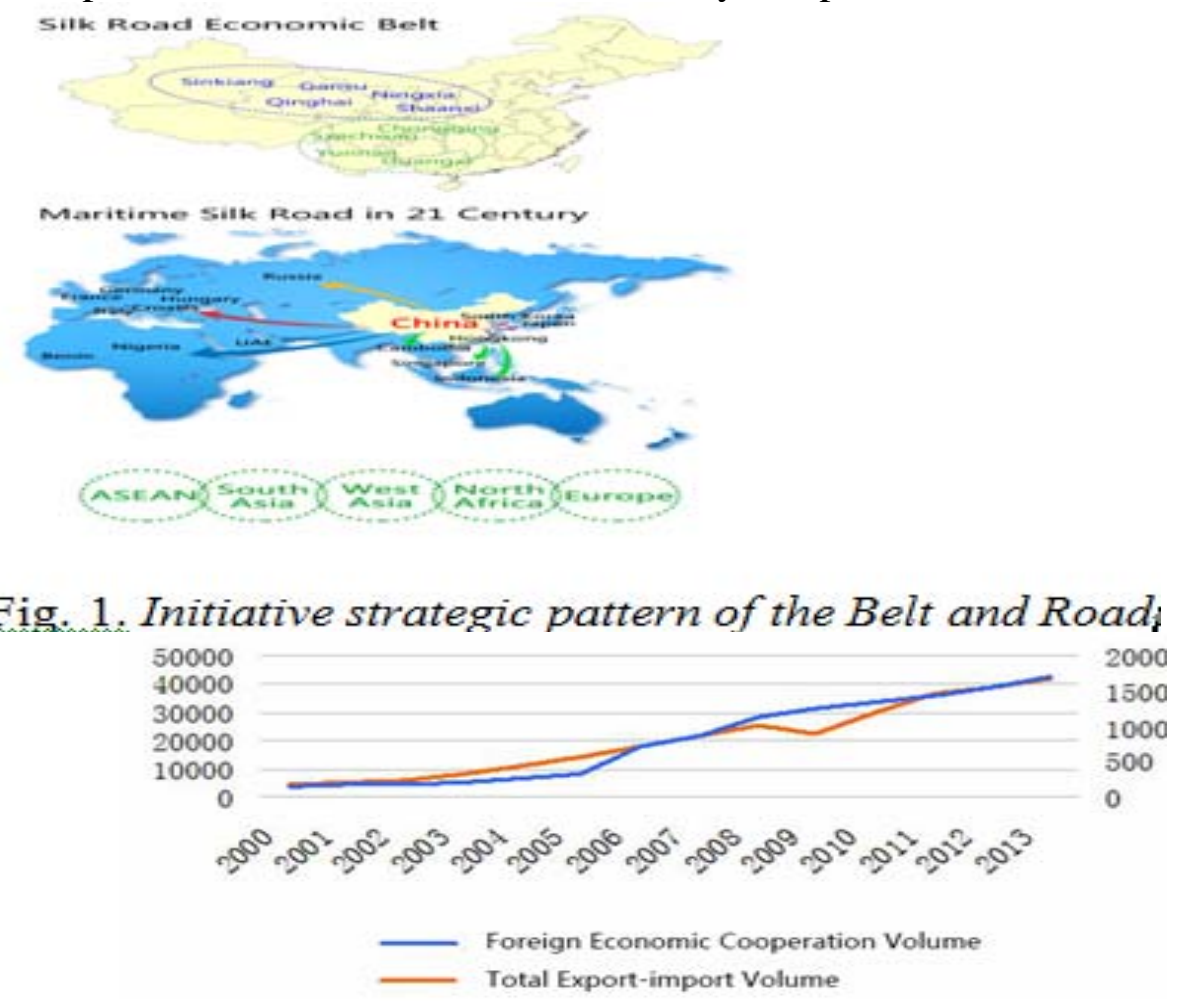

Figure 2 The basic situation of China's foreign trade in $2000 \sim 2013$ (billion dollars)

\subsection{Culture industry development difficulties - a case study of animation industry}

Apparently lack of creative ability of cultural products; a severe shortage of cultural professionals, 
especially the cultural and creative professionals and management personnel as well as financial support, which will become a bottleneck constraining of China's culture industry development ${ }^{[10]}$. Animation industry is an important part of China's culture industry, in the culture industry doubling plan during "12th Five-Year" in focus proposed to vigorously develop the animation industry. under the protection of our country strong support at all levels of policy, actively cooperate with the provinces and China's unique comparative advantage, though China's animation industry gained some development.

In the manufacture of anime, made in China are not uncommon, the lack of it is "created in China". China animation, the earliest introduction of American and Japanese products, which can be understood in the early stage, but in later works, still exist constantly plagiarizing and imitating foreign cultural products phenomenon; Animation manufacture lack of a complete industrial chain, either from aspects of the original painting, the manufacture, design, and the director are relatively backward; and most of the animation enterprise dimensions slants small, inefficient output value of long-term, animation products often face huge investment, high loss, in international trade competition can't play their comparative advantages, nearly $50 \%$ of the animation business to survive, participate in the international cultural products plus, outsourcing, of technical requirements are relatively low part, but this does not for China's animation industry bring progress, will only make our country in the international trade of cultural products in long-term disadvantage.

\section{Suggestions of countermeasures on promoting culture industry international trade}

\subsection{Actively create an all-good trading environment}

On the one hand, we must continue to promote the balanced development of China's culture industry in regions, government response to ensure the material of culture industrial development, formulate trade policy according to time and place, construct culture industry trade development mode with Chinese characteristics, strive to establish a bilateral or multilateral customs cooperation mechanisms to ensure the healthy development of international economic and trade cooperation between the partners including the countries along "The Belt and Road", and promote the healthy development of culture industry. On the other hand, continue to improve the international communicate environment, strengthen the cultural industry international trade cooperation between countries the infrastructure construction and information construction. The production of cultural products mainly rely on the technical support, so one side we have to strengthen cooperation between countries of highway, railway, aviation and so on at the port conditions and infrastructure construction, and actively promote traffic facilitation agreement signed with the international trade partners, harmonization of national transport standard, reduce transportation costs, improve the convenience of trade cooperation; the other side we should actively create a communication environment of culture technology, give policy encourage and fund support to international research cooperation and technology communications between the scientific researchers, introduce advanced technology equipment to save communication cost for the outsourcing of international cultural products trade project communication, promote international cultural enterprise knowledge transfer, for cultural products manufacturing reserve technology.

\subsection{Make efforts to cultivate talents, solve the shortage of the cultural industry talents}

Culture industry's unique advantages, which include low consumption, high-yield, strong industry relevance, obvious spillover effect and so on, brings the potential to create wealth and positions. Large demand for talents, caused by the international cultural products trade, can greatly attract a lot of talents to participate in international cultural communication, using "learning by doing" and constantly improve the cultural personnel professional quality and technical level. On the one hand, the government should set up special funds to support the universities and research institutes with outstanding contributions in the production of cultural products, and take preferential measures for the cultural enterprises in the international trade of cultural products. On the other hand, the government should actively encourage the development of cultural industry virtual cluster, which is 
not only limited in the domestic cultural enterprises but also attracting more foreign culture enterprise to technical communication, studying hard the advanced technology in the developed countries, especially in the international trade of the major competing countries; continue to play a dominant industry, such as the animation industry, strengthen the relevant aspects of talent training, reserve personnel.

\subsection{Risk avoidance}

First of all, we must face the system risk, which is the comprehensive production of political, economic and social factors, and also one of the key factors affecting international trade. It originates from the political stability, the nationalization of foreign capital, and the uncertainty of international economic policies, etc. Although many of these risks are not controllable, there are rules to follow. Our country should establish risk early warning system, monitor the risk of overseas investment macro environment for these often cooperation culture enterprises with our country, understand national politics and policy changes of culture industries, and analyze the economic fluctuation of cooperation countries scientifically and reasonably, to advise the international trade of culture industry in our country, avoid risks and large economic loss timely.

Secondly, in order to cope with the financial risks of international trade in advance, we must perfect the construction of the financial sector. On the one hand, encourage international trade cooperation countries in culture industries choose the financial institutions with sound risk management mechanism to provide international payment services, set up branch structure each other among the cooperation of countries, and establish and perfect the credit sharing mechanism $^{[11]}$.On the other hand, continue efforts to realize the internationalization of RMB, both in the going global and bringing-in process, and the domestic cultural enterprises provide RMB lending services for overseas cultural enterprises, institutions and cooperation projects, by outsourcing, outsourced, and foreign trade processing trade way ${ }^{[12]}$.

Finally, the cultural industry has particularity, so we also have to face cultural risks. Due to the cultural distance differences among countries, or the differences of culture, generally, the higher the cultural similarity, the smaller enterprises face the business and management culture conflict in investment countries, or the smaller cultural risks. China must consider problems caused by culture cautiously in prevention when selecting international culture products trade partners, in order to reduce unnecessary loss, and minimize risk while realizing the multiplication of culture products ${ }^{[13]}$.

\section{Acknowledgment}

This research was financially supported by NSSFC(14BSH052) and NSFC(71401092).

\section{References}

[1] ZHANG Mingzhi. An Analysis on the Mechanism of How International Outsourcing Affects the Industrial Upgrading in Developing Countries[J].Journal of International Trade, 2008(1):44-47.

[2] Zheng Ruogu. International outsourcing and industrial upgrading and structure transition in China [D] Shang Hai: Shang Hai University of Finance and Economics,2011.

[3] Tang Yihong, Yan Jinguang.The Effect of Offshore Outsourcing on China's Export Structure[J]. Nankai Journal,2006(3):20-28.

[4] He Yixia. The silk road economic belt: strategic considerations, prospects and development train of thought[J]. Contemporary World and Socialism,2014(4):76-80.

[5] Lu Feng. The economics observation of contemporary service outsourcing: a economics perspective of products within the division[J].The Journal of World Economy,2007(8):22-35. 
[6] Zhang Qiuju,Zhu Zhongdi. Empirical Study on International Outsourcing and Technology Progress : A Test of Long-term and Short-term Causality based onVECM [J]. World Economy Study,2008(6):74-88.

[7] Xu Yi,Zhang Erzhen. FDI,Outsourcing and Technology Innovation:Empirical Research Based on Input-output Table Data [J]. The Journal of World Economy,2008(9):41-48.

[8] Cheng Yunjie. The New Opportunities and Challenges which "The Silk-Road Economic Belt" construction had brought to the foreign trade of our country[J].Economic Review,2014(6):92-96.

[9] Wang Ronghui. The Strategies and Paths during the development of Cultural enterprises internationalization [J]. China Publishing Journal,2012:31-33.

[10]Chen Fashi. Analyses the Comparative Advantage of Cultural Industry in Our Country [J]. Productivity Research,2010(6):191-200.

[11] Chen Gui,Ding Zhijie.The Economic and Trade Cooperation between China and Central Asian Countries under the background of The Silk -Road Economic Belt [J].Journal of Soochow University(Philosophy \& Social Science Edition), 2015(1):119-125.

[12] Guo Aijun,Mao Jinhuang. A Study on the Industry Positioning and Synergetic Development of the Node Cities in China during the construction of "The Silk-Road Economic Belt" [J]. Journal of Northwest University(Philosophy and Social Sciences Edition),2015,45(4):18-27.

[13]Shi Shurong, Li Jianjun. The Risk Early Warning Research of Investment's Macro Environment Overseas in enterprise in China [J]. Economic Review,2015(8):101-106. 